\title{
Effects of myocardial fibrosis and ventricular dyssynchrony on response to therapy in new-presentation idiopathic dilated cardiomyopathy: insights from cardiovascular magnetic resonance and echocardiography
}

Darryl P Leong ${ }^{1 *}$, Adhiraj Chakrabarty ${ }^{2}$, Nicholas Shipp ${ }^{3}$, Payman Molaee $^{3}$, Per Lav Madsen ${ }^{4}$, Lucas Joerg $^{4}$, Thomas Sullivan ${ }^{5}$, Hugh Greville ${ }^{6}$, Stephen G Worthley ${ }^{3}$, Carmine G De Pasquale ${ }^{4}$, Prashanthan Sanders ${ }^{3}$, Joseph B Selvanayagam²

From 2011 SCMR/Euro CMR Joint Scientific Sessions

Nice, France. 3-6 February 2011

\section{Objectives}

To determine whether the extent of myocardial fibrosis by late-gadolinium enhancement cardiovascular magnetic resonance (LGE-CMR), and echocardiographic ventricular dyssynchrony can independently predict response to medical therapy in patients with newly-diagnosed idiopathic dilated cardiomyopathy (DCM).

\section{Background}

Myocardial fibrosis and ventricular dyssynchrony are frequent findings in DCM. Although previous studies have reported poor prognosis with the presence of myocardial fibrosis in DCM, they focussed on patients with established cardiomyopathy, and did not characterise patients early in the disease course and may not have included those with significant improvement in $\mathrm{LV}$ function soon after diagnosis. Hence, the degree of myocardial fibrosis and ventricular dyssynchrony at initial presentation, and their role in perpetuating left ventricular (LV) dysfunction in DCM remains unclear. We hypothesised that extent of myocardial fibrosis by the LGE-CMR technique and echocardiographic ventricular dyssynchrony are independent predictors of failure of improvement in LV function in new-onset DCM.

\footnotetext{
'Department of Cardiovascular Medicine, Flinders Medical Centre, Adelaide, Australia, The University of Adelaide, Adelaide, Australia, The Flinders University of South Australia, Adelaide, Australia Full list of author information is available at the end of the article
}

\section{Methods}

Patients with a new diagnosis of DCM (LV ejection fraction $(\mathrm{EF}) \leq 45 \%$ ) made within the preceding two weeks were recruited. Patients underwent LGE-CMR, echocardiography, 6-minute-walk testing, cardiopulmonary exercise testing, and blood sampling for measurement of serum NT-pro-BNP concentration at baseline. Baseline patient characteristics were compared with a cohort of healthy volunteers. Myocardial fibrosis by LGE-CMR was identified by experienced observers blinded to patient outcome, and was quantified by planimetry for calculation of fibrosis mass. LV systolic function was reassessed after 5 months optimal medical therapy.

\section{Results}

Sixty-eight patients with DCM and 19 healthy volunteers were studied. DCM patients were studied a median 12.5 days following diagnosis. Compared to healthy controls, DCM patients exhibited poorer functional capacity, higher serum NT-pro-BNP concentration, and greater inter- and intraventricular dyssynchrony. Twenty-four percent of DCM patients exhibited LGE at diagnosis, whereas no LGE was observed amongst controls. Within DCM patients with LGE, the mean fibrosis mass was 2.2 $\pm 1.3 \mathrm{~g}$. On multivariate analysis, strain dyssynchrony index, and fibrosis mass were independent predictors of change in LVEF over time $(\mathrm{p} \leq 0.001)$ (Table 1). LGECMR conferred additive prognostic value over and above 
Table 1 Uni- and Multivariate Model of Prognostic Factors for Change in LVEF

\begin{tabular}{|c|c|c|c|c|}
\hline Variable & Univariate model & & Multivariate model & \\
\hline & Coefficient $(95 \% \mathrm{Cl})$ & p-value & Coefficient $(95 \% \mathrm{Cl})$ & p-value \\
\hline Age & $-0.06(-0.3$ to 0.2$)$ & 0.8 & & \\
\hline Gender & $-4(-10$ to 3$)$ & 0.8 & & \\
\hline 6-minute walk distance $(\mathrm{m})$ & $0.03(-0.01$ to 0.08$)$ & 0.3 & & \\
\hline $\mathrm{VO}_{2}$ PEAK $(\mathrm{mL} / \mathrm{kg} / \mathrm{min})$ & $0.3(-0.7$ to 1.3$)$ & 0.6 & & \\
\hline Tissue Doppler dyssynchrony index (ms) & $-0.07(-0.3$ to 0.2$)$ & 0.7 & & \\
\hline$E / E^{\prime}$ & $0.04(-0.2$ to 0.3$)$ & 0.8 & & \\
\hline Left atrial volume $(\mathrm{mL})$ & $-0.02(-0.1$ to 0.1$)$ & 0.8 & & \\
\hline TAPSE (cm) & $-1(-10$ to 7$)$ & 0.7 & & \\
\hline Interventricular mechanical delay (ms) & $-0.1(-0.3$ to 0.05$)$ & 0.3 & $0.3(-0.06$ to 0.6$)$ & 0.1 \\
\hline NT-pro BNP $(\mu \mathrm{g} / \mathrm{L})$ & $-1(-2$ to -0.09$)$ & 0.007 & $-0.2(-2$ to 1$)$ & 0.8 \\
\hline QRS-duration (ms) & $-0.14(-0.3$ to -0.02$)$ & 0.004 & $-0.3(-0.7$ to 0.1$)$ & 0.2 \\
\hline Strain dyssynchrony index (ms) & $-0.1(-0.2$ to -0.06$)$ & 0.04 & $-0.1(-0.2$ to -0.04$)$ & $<0.001$ \\
\hline Fibrosis mass (g) & $-7(-11$ to -3$)$ & $<0.001$ & $-7(-11$ to -4$)$ & $<0.001$ \\
\hline
\end{tabular}

clinical and echo-dyssynchrony parameters for the prediction of improvement in LVEF.

\section{Conclusions}

The extent of myocardial fibrosis is a powerful predictor of a negative response to medical therapy in new-presentation DCM, and LGE-CMR may thus be an important risk-stratifying investigation in these patients. Accurate risk stratification may permit more targeted pharmacological and device therapies for patients with newly-diagnosed DCM.

\section{Author details}

${ }^{1}$ Department of Cardiovascular Medicine, Flinders Medical Centre, Adelaide, Australia, The University of Adelaide, Adelaide, Australia, The Flinders University of South Australia, Adelaide, Australia. ${ }^{2}$ Department of Cardiovascular Medicine, Flinders Medical Centre, Adelaide, Australia, The Flinders University of South Australia, Adelaide, Australia. ${ }^{3}$ University of Adelaide, Adelaide, Australia, Adelaide, Australia. ${ }^{4}$ Department of Cardiovascular Medicine, Flinders Medical Centre, Adelaide, Australia, Adelaide, Australia. ${ }^{5}$ Discipline of Public Health, University of Adelaide, Adelaide, Australia. ${ }^{6}$ Department of Respiratory Medicine, Royal Adelaide Hospital, Adelaide, Australia.

Published: 2 February 2011

doi:10.1186/1532-429X-13-S1-P338

Cite this article as: Leong et al:: Effects of myocardial fibrosis and ventricular dyssynchrony on response to therapy in new-presentation idiopathic dilated cardiomyopathy: insights from cardiovascular magnetic resonance and echocardiography. Journal of Cardiovascular Magnetic Resonance 2011 13(Suppl 1):P338.
Submit your next manuscript to BioMed Central and take full advantage of:

- Convenient online submission

- Thorough peer review

- No space constraints or color figure charges

- Immediate publication on acceptance

- Inclusion in PubMed, CAS, Scopus and Google Scholar

- Research which is freely available for redistribution

Submit your manuscript at www.biomedcentral.com/submit
C Biomed Central 